\title{
Ultimate Limit State Design of Spread Foundations in The Case of Uplift
}

\author{
Witold Bogusz \\ Department of Geotechnics and Foundation, Building Research Institute, Warsaw, Poland \\ E-mail: w.bogusz@itb.pl
}

\begin{abstract}
As vast majority of spread foundations are never subjected to vertical uplift loads, the subject of uplift capacity in such cases is barely covered by current European standards. Although the limit state design due to uplift is a subject of a section 10 of Eurocode 7, it mainly covers the possibility of a hydraulic failure while taking into the account any destabilizing variable actions. However, in the case of separate foundations of lattice towers used as support structures for overhead power lines, the uplift capacity of spread foundations often governs the design. The rules for the design of these structures are included in the informative annex M of EN 50341-1: 2012 Overhead electrical lines exceeding AC $1 \mathrm{kV}$ - Part 1: General requirements - Common specifications. Rules presented in this standard differ significantly from those presented in Eurocode 7. The purpose of this paper is to present the design approaches for the limit state design of spread foundations subjected to uplift, while the differences between design rules and resulting variation of reliability are the primary concerns.
\end{abstract}

Keywords: Spread foundations, limit state design, uplift, Eurocode 7, overhead power lines.

Conference topic: Design experiences and theoretical solutions.

\section{Introduction}

In the vast majority of cases when spread foundations are designed, their bearing capacity in compression is the main concern for geotechnical engineers, as well as the key factor guiding the design. In some cases, when compressive vertical load is relatively small, the tilt, often limited by the allowable load eccentricity, is the next important limit state to consider. In standard design practice, occurrence of the uplift force acting on the foundation is rare, and rather avoided. However, uplift resistance of a spread foundation is the primary concern in some particular cases.

According to IEEE Guide (2001) and EN 50341-1: 2012 , the uplift capacity of a spread foundation is often the controlling condition in the case of geotechnical design for support structures of transmission lines with separate footings for each leg. Some load cases, usually caused by extreme wind load or sudden failure of the conductors (overhead lines), will result in vertical compression loading for some of the foundations, with accompanying vertical uplift in the others (Fig. 1). In some cases, like terminal or heavy angle towers, where direction of the transmission line is changed at the specific tower, it may result in uplift as a normal long-term or frequently occurring condition (Eskom 2005; Pacheco et al. 2008). To provide resistance to uplift, spread foundations are often preferred to pile foundations as their design is relatively simpler; furthermore, their construction does not require specialised drilling rigs and deep geotechnical investigation. It is especially important in areas where access by heavy rigs and equipment is not possible or economically justified.

This paper presents the general background and the approaches for uplift resistance verification for spread foundations, available in accordance with the current European standards: EN 1997-1: 2008 and EN 50341-1: 2012; their main assumptions, simplifications and resulting uncertainties are discussed. Finally, a basic comparison of resulting overall factors of safety is presented, based on the partial factors proposed in these standards and used in Polish practice.

\section{Failure mechanism for spread foundation in uplift}

Uplift of a spread foundation is resisted by its selfweight, earth surcharges and shear forces in the soil (EN 50341-1: 2012). Loaded in uplift, spread foundation can fail in distinctly different modes (IEEE 2001), which may depend on:

- the construction procedure;

- foundation depth;

- soil properties;

- in-situ soil stress.

Two main failure modes can be identified in uplift (Kulhawy et al. 2003; Pacheco et al. 2008), one for shallow, and one for deep spread foundations. For the former, most commonly used, a vertical shear pattern or cone/wedge failure along inclined planes can occur; for the latter, a type of punch-through failure might take place above the foundation.

According to IEEE Guide (2001), in some cases, variations of abovementioned mechanism can occur; for stiff soils with well compacted backfill, a combined vertical shear and cone/wedge failure may develop. While for deep foundations and with relatively loose backfill, when the vertical shear is greater than upward bearing capacity of the backfill, punching or bearing capacity failure is possible.

Generalized uplift capacity model, presented at Figure 2, shows the possible combination of failure 


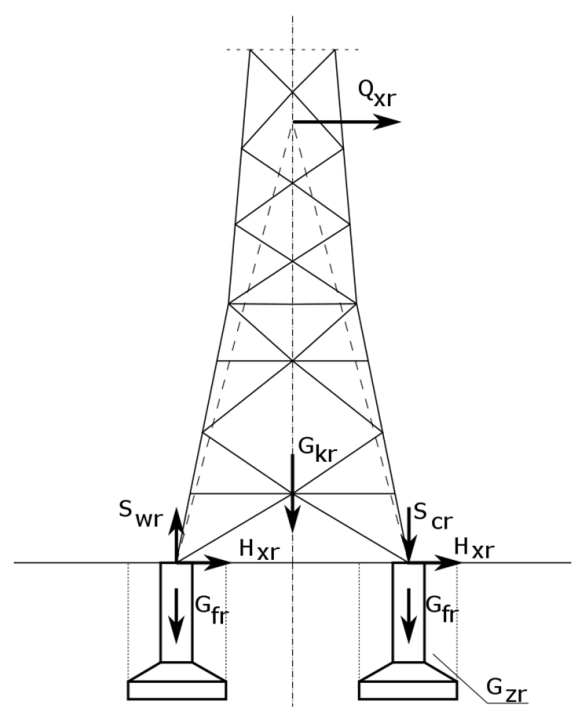

Fig. 1. Schematic loading of a separate footings of a lattice tower (Source: PN-80/B-03322: 1980) where:

$Q_{x \mathrm{r}}-$ design value of the horizontal

$G_{k r}$ - design value of the self-weight of the support;

$S_{c r}-$ design value of the vertical compression load on the single foundation;

$S_{w r}$ - design value of the vertical uplift load on the single foundation;

$H_{x r}$ - design value of the horizontal load on the single foundation;

$G_{f r}$ - design value of the self-weight of the foundation;

$G_{z r}$ - design value of the self-weight of the soil above the foundation.
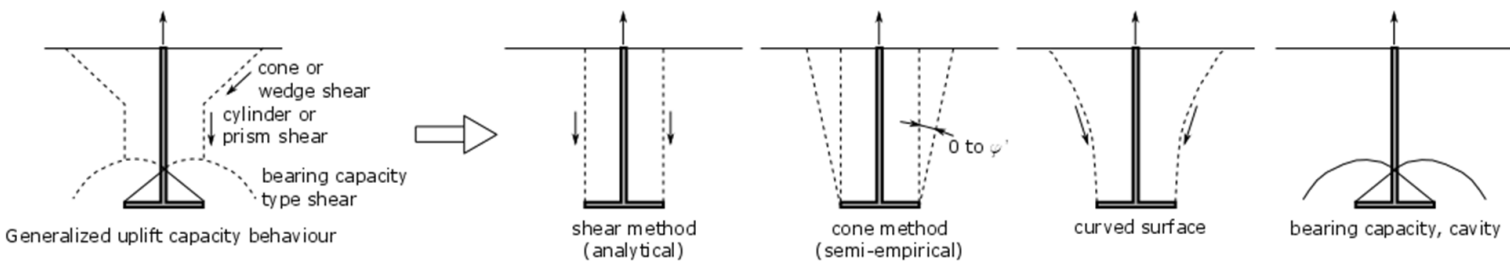

Fig. 2. Possible failure mechanisms in uplift and calculation models

(Source: IEEE 2001; Kulhawy et al. 2003)

modes that take place when spread foundation fails under the tensile load. Additionally, this general model can be separated into specific failure modes, which are often the base for calculation models presented in standards (i.e. EN 50341-1: 2012), guidelines (i.e. IEEE, 2001) and literature (Kulhawy et al. 2003).

Most calculation models used in design are simplified analytical approaches to the issue concerning uplift resistance, or semi-empirical methods based on general behavioural model presented at Figure 2. The IEEE (2001) guide distinguishes four categories of methods, which can be used, each with some limitations:

- the cone or wedge methods - which assume the uplift resistance results only from the weight of the foundation and the soil enclosed within the cone/wedge - at a zero degree angle they give conservative results, disregarding soil strength and stress state; while for angle greater than zero, they substitute an equivalent weight of the soil for the soil stresses and strength;

- the shear methods - assume a vertical shear surface, taking into account the shear strength of the soil - these types of methods are described in more details in subsequent sections of the paper;
- the curved surface methods - in which the resistance is provided by the weight of the soil in the curved zone; according to Pacheco et al. (2008), the actual failure obtained from tensile tests in stiff soils is often curvilinear.; however, it may be replaced by an equivalent simplified conical surface;

- a bearing capacity or cavity expansion methods - valid mainly for deep spread foundations.

\section{Basic equilibrium model}

The simplest analytical, equilibrium model (Kulhawy et al. 2003), assumes the vertical shear lines. In the most basic form, the total uplift capacity, $Q_{u}$, in vertical shear mode can be evaluated (IEEE Guide 2001) as:

$$
Q_{u}=W+Q_{s u}+Q_{t u},
$$

where: $W-$ is the sum of the weight of the foundation $\left(W_{f}\right)$ and soil $\left(W_{s}\right)$ within the volume $B \times L \times D ; Q_{s u}$ - is side resistance; $Q_{t u}$ - is tip resistance.

The side resistance, $Q_{s u}$, can be evaluated as:

$$
Q_{s u}=U \cdot \sum \sigma_{v, i} \cdot K_{i} \cdot \tan \delta_{i} \cdot d_{i},
$$


where: $U$ - circumference of the foundation base; $\sigma_{v, i}-$ vertical effective stress at mid-depth of the layer; $K_{i}-$ operative horizontal stress coefficient at mid-depth of the layer; $\delta_{i}$ - interface friction angle at mid-depth of the layer; $d_{i}$ - thickness of the layer.

According to EPRI Report (1995) and Kulhawy et al. (2003), the tip resistance under undrained conditions develops from suction forces, and can be estimated by:

$$
Q_{t u}=\left(-\Delta u-u_{i}\right) \cdot A_{t i p},
$$

where: $u_{i}$ - initial pore water pressure at the foundation base; $\Delta u$ - change in pore water pressure caused by undrained loading; $A_{\text {tip }}$ - base area.

For long-term (drained) conditions, the tip resistance can be assumed to be zero, as it might develop only from bonding of concrete with the underlying soil, thus, depending on the tensile strength of the soil. However, disregarding suction in short-term (undrained) conditions may be advisable, since it is often governed by factors beyond geotechnical engineer's control, and omitting it allows us to err on the side of safety. Moreover, the addition of suction to the total uplift resistance assumes that no breakaway is possible while the foundation is fully bonded with the soil at the interface, which is often not the case (Li et al. 2015).

IEEE (2001) guideline provides the design procedure based on the possible failure models presented at Figure 2. Firstly, the uplift capacity is calculated as for the basic equilibrium model (Kulhawy et al. 2003). Secondly, calculated capacity is modified for cone/wedge breakout. Finally, upper bound of the capacity is calculated for punching capacity. This method does not have limitations contrary to the methods described previously.

\section{Factors affecting the resistance to uplift}

\section{The construction procedure}

From geotechnical point of view, the construction of a spread foundation subjected to uplift does not have to differ from the one resisting compression only. The construction phases consist of: excavation, placing the foundation, backfilling over, and if necessary, around the foundation.

The main difference lies in the form and the extent of the excavation (Fig. 3). It can have either vertical or inclined walls, while the excavation itself can be either neat or oversized (IEEE 2001). In the case of neat, vertical excavations, the distinction can be made between the excavation with or without an undercut (EN 503411: 2012). The construction procedure may promote specific, foreseeable failure mechanism, i.e. shear failure in backfill for an inclined, oversized excavation, or shear failure in native soil in the case of neat, vertical excavation with an undercut.

In most cases, the shallow spread foundation subjected to uplift will fail in vertical shear, either cylindrical or rectangular, depending on the shape of the base. The difference in parameters between the native soil and the backfill will play a significant role in the side resistance; the uplift resistance might be strongly dependant on the backfill compaction. The weaker of the backfill and the native soil will control the resistance, as usually there is no reduction of shear strength at the interface between both soils. Kulhawy et al. (2003) noted that for loose or medium dense native soils, only a modest increase in uplift capacity will be noted with the increase of backfill density; while in the case of dense native soil, with increasing depth, the increase will be more noticeable.

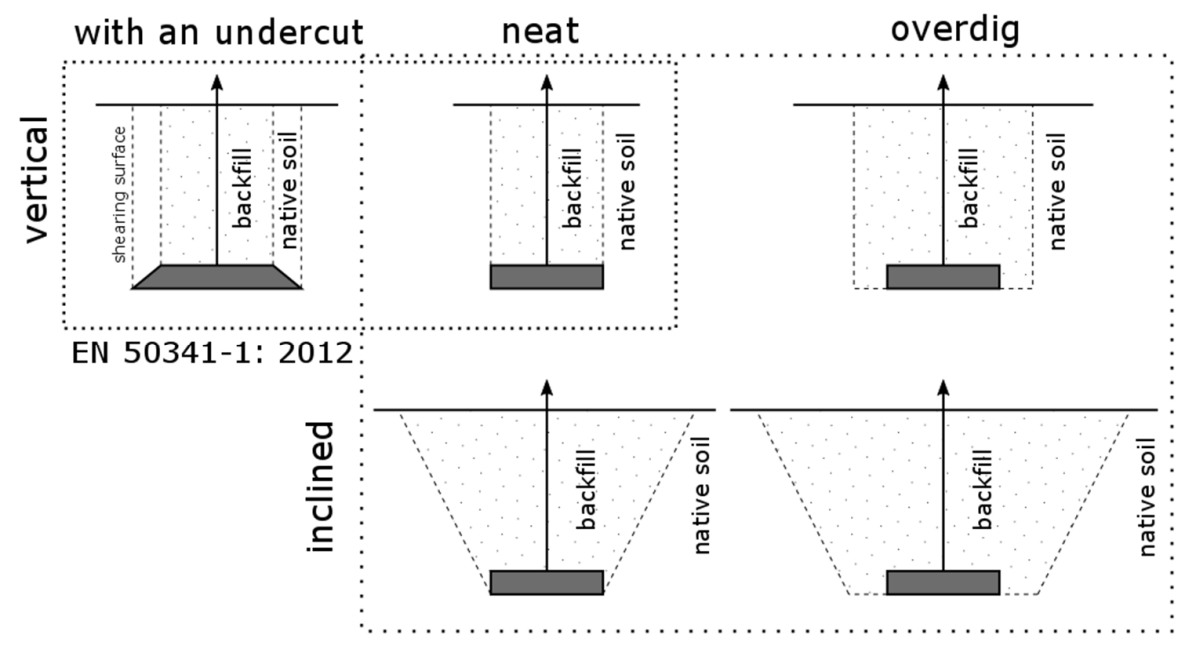

IEEE (2001)

Fig. 3. Possible excavation and construction procedure variations

(Source: IEEE 2001; EN-50431-1: 2012) 


\section{Foundation depth}

The failure surface reaches the ground level in shallow mode and the resistance is provided by the foundation base only; while in deep mode, the shaft of the foundation can provide additional resistance (Fig. 4). The failure of the foundation is governed by the lower of the uplift resistances for the shallow and deep mode. Based on that, a simple distinction can be made between both modes by the means of identifying the critical depth at which the mode of failure changes. Pacheco et al. (2008) suggested that the critical depth is no less than two times of the diameter or the width of the foundation; thus, typically for the supports of the overhead power lines, the failure will occur in shallow mode.

\section{Soil properties}

Significant differences in the resistance calculation procedure can result from the soil properties. First and foremost, the mode of failure (Fig. 4) will depend on the strength of the soil. As a limiting value for the distinction between weak and stiff soil, the angle of internal friction of $15^{\circ}$ was used in $\mathrm{PN}-80 / \mathrm{B}-03322$; the exact calculation model, which may be considered as a semiempirical method, used in the analysis was based primarily on the strength of the soil. For soils of low shear strength $\left(\varphi \leq 15^{\circ}\right)$, two modes dependant on the foundation depth were given. However, seldom were they used when the backfill was not made of the local soft soil. For soils of medium to high shear strength $\left(\varphi>15^{\circ}\right)$, only one model was presented, for a shallow spread foundation.

In the case of analytical approach, based on the basic equilibrium model, if the soil is fine-grained (cohesive), a distinction between short-term resistance (undrained, governed by the undrained shear strength) and long-term (drained, governed by the effective shear strength parameters) has to be made. Since the most unfavourable loading conditions will usually result from variable actions (i.e. wind load), a short-term resistance will guide the design for fine-grained soils. Naturally, the shear strength parameters will directly impact the value of the shear resistance along the vertical shear surface.

\section{In-situ soil stress}

For the analytical methods of estimating the uplift resistance of a spread foundation, a horizontal stress coefficient plays an important role in calculating the side resistance. According to IEEE (2001) guide, it may vary from the value equal to $K_{a}$ for native soil with loose backfill, up to the value exceeding 1,00 for well compacted backfill. For normally consolidated soils, a value of $K_{0}=1-\sin \varphi$ ' may be conservatively assumed in long-term conditions. A careful consideration should be given to the choice of this parameter as it may significantly vary in in-situ conditions due to the construction procedure, soil disturbance and the effect of compaction of the backfill.

\section{Coverage by current European standards}

\section{EN 1997-1:2008 Eurocode 7}

The ultimate limit state concerning uplift of any type of a geotechnical structure is covered by the section $2-$ Basis of geotechnical design, and section 10 of Eurocode 7 - Hydraulic failure. The former provides the general distinction between different limit states and

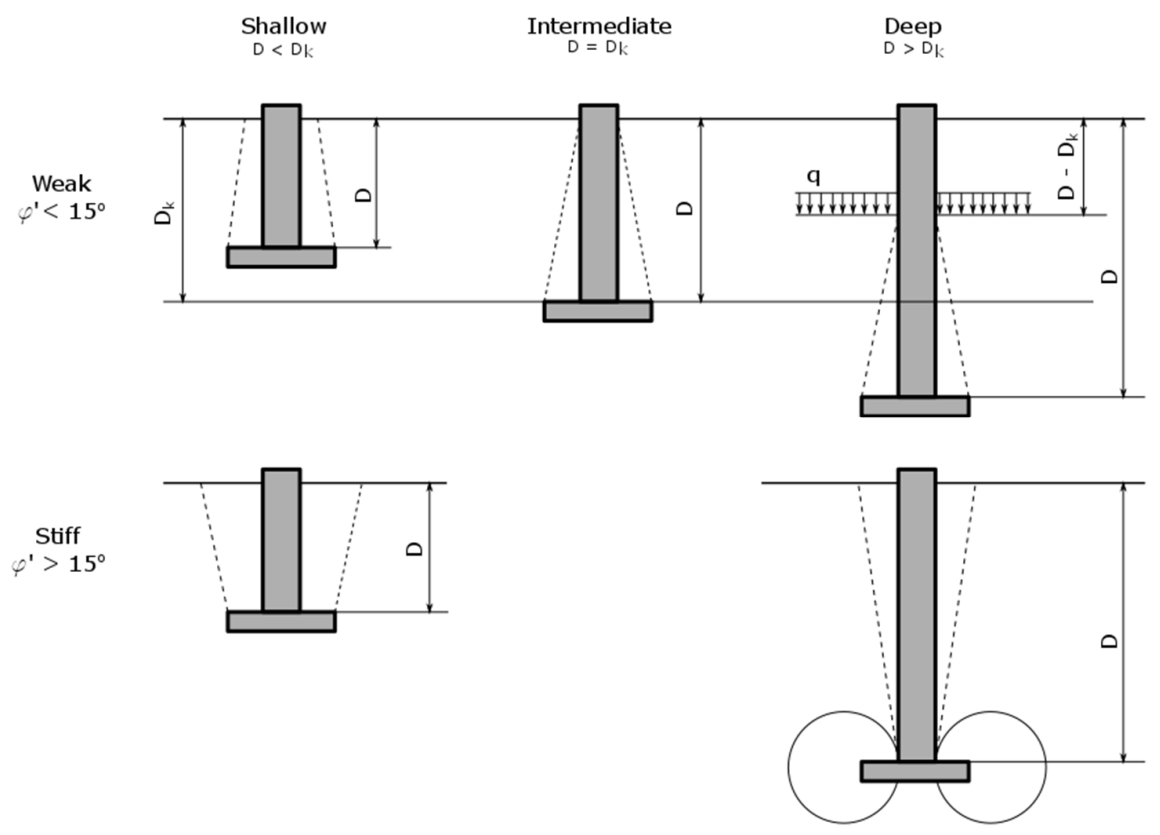

Fig. 4. Possible failure mechanisms in uplift and calculation models depending on the strength of the soil and embedment depth (Source: PN-80/B-03322; Pacheco et al. 2008) 
basic rules for verification procedure in the case of uplift (UPL); together with the normative Annex A, it also provides partial factors (not modified in Polish National Annex PN-EN 1997-1: 2008/Ap2: 2010), which are to be used in order to provide sufficient reliability level assumed by the Eurocode. The general approach of Eurocode 7, to check the uplift resistance of the foundation, makes its use flexible when different structures are considered and different calculation models are used. However, no specific calculation models are given for the spread foundation subjected to the uplift force. The choice of the model is left entirely at the geotechnical engineer's own discretion, either based on the models available in literature, previous experience or provided in complementary standards if they are available.

The verification is carried out by the comparison of the design value of the combination of destabilising permanent and vertical actions, $V_{d s t, d}$, with the sum of the design value of the stabilising permanent actions and the design value of any additional resistance to uplift, according to the inequality:

$$
V_{d s t, d} \leq G_{s t b, d}+R_{d},
$$

where: $G_{s t b, d}$ - design value of stabilising permanent vertical action $\left(\gamma_{G, s t b}=0,90\right) ; R_{d}-$ design value of any additional resistance to uplift $\left(\gamma_{R}=1,25-1,40\right.$, depending on the source of the resistance).

The design value of the combination of destabilising permanent and variable vertical action, $V_{d s t, d}$, is calculated as:

$$
V_{d s t, d}=G_{d s t, d}+Q_{d s t, d}
$$

where: $G_{d s t, d}$ - design value of destabilising permanent action $\left(\gamma_{G, d s t}=1,00\right) ; Q_{d s t, d}-$ design value of destabilising variable action $\left(\gamma_{Q, d s t}=1,50\right)$.

Additionally, according to Eurocode 7 application rule (2), paragraph 2.4.7.4, any additional resistance to uplift may be treated as a stabilising permanent action $\left(G_{s t b, d}\right)$. While this possibility simplifies the design and the UPL verification procedure, it raises the issue of resulting difference in partial factors; in the case of permanent destabilizing action without the variable component, the equivalent global safety factor in uplift can be as low as 1,11 .

In the case of the foundations used for transmission power lines, further complications result from the distinction of permanent and variable actions. In most cases, the structural design of a support structure, i.e. lattice tower with separate footings, will result in design value of loads acting on these foundations; quite often, no distinction is made between permanent or variable actions, much as whether a specific load acts as a stabilising or destabilising action. Even a self-weight of the conductor (an overhead line) can act as a stabilising permanent action in the case of mid-line tower, while destabilising in the case of terminal or heavyangle towers.

\section{EN 50341-1: 2012}

The two limit states considered in EN 50341-1: 2012 are STR and GEO, as defined according to EN 1997-1: 2008. However, in the case of uplift, resistance is treated also as GEO limit state, rather than UPL. The calculation model used to determine the foundation resistance to uplift may consists of one of the following:

- an analytical model;

- a semi-empirical model;

- numerical model.

The standard allows for the use of models given in EN 1997-1, National Annexes, literature, and those which have been used with satisfactory practical experience. Furthermore, while using analytical model, EN 50341-1: 2012 allows for the use of one of two design approaches presented in Eurocode 7; either DA2 or DA3. An example of an analytical and a semi-empirical model is given in informative annex M. However, the proposed resistance factors, $\gamma_{r}$, are associated with the specific calculation models, without any value given for provided analytical model.

The informative Annex M to EN 50341-1: 2012 contains sample analytical models for uplift resistance calculation. Presented models are applicable for concrete stepped block footings in soils. The only two cases considered are for neat excavation with vertical walls, with (case a) or without (case b) an undercut. The ultimate limit state of a foundation shall be verified as:

$$
E_{u, d} \leq R_{u, d},
$$

where: $E_{u, d}-$ the total design effect of actions on foundations resulting from all the actions on the supports and from the supports themselves, with partial factors included in the calculation of actions on the supports, according to chapter 4 of the standard; $R_{d}$ - the design resistance of the foundation, which may be calculated for the analytical model as:

- Design Approach 2:

$$
R_{u, d}=\left(R_{w}+R_{s}\right) / \gamma_{R},
$$

where: $R_{w}$ - weight of the foundation and the soil above the foundation; $R_{s}$ - uplift side resistance; $\gamma_{R}-$ the partial factor applied to foundation uplift resistance (value not specified in the standard).

- Design Approach 3:

$$
R_{u, d}=R_{w}+R_{s} / \gamma_{M},
$$

where: $\gamma_{M}$ - the partial factor applied to the ground properties (1,25 - for short-term conditions, 1,40 for long-term conditions).

Contrary to IEEE (2001) guidelines, the EN 50341-1: 2012 standard does not differentiate the shear strength with the quality of compaction of the backfill. An assumption is made that the backfill density and its angle of shearing resistance are equivalent to those of the native soil if the backfill has been composed of the same soil and is well compacted. No guidance is pre- 
sented concerning the cohesion, the undrained shear strength or the parameters of compaction. In practice, this simplification can result in underestimation of shear strength of well compacted loose sands or overestimation in the case of overconsolidated soils. Furthermore, the validity of the design assumptions will depend greatly on the quality of execution of the compaction at the construction site, requiring thorough supervision and verification.

Additionally to the analytical model proposed in annex M, a semi-empirical model for resistance estimation is also proposed. In the case of separate stepped block foundations, the uplift force is resisted by the selfweight of the foundation and the weight of the soil enclosed by the angle of earth frustum. This model is similar to the cone or wedge model presented in IEEE Guide (2001). EN 50341-1: 2012 proposes the resistance factor of 1,10 while using this method.

The methods proposed in the annex $\mathrm{M}$ are the simplified versions of the models available in the literature, other standards and guidelines (i.e. IEEE 2001). In most cases, they may be used without further consideration for additional modes of failure. Other calculation models, such as presented in PN-80/B-03322, can also be used in the design of spread foundations for support structures. However, the use of appropriate partial factors for the resistance is necessary, which would require the calibration of the method. No guidance is given for the use of numerical models.

What is of significant importance, the EN 50341-1: 2012 standard introduces the concept of strength coordination, following the common practice in design of overhead power lines. The failure of a single support structure in a transmission line, often being a part of a critical infrastructure, can have significant financial consequences; more importantly than the cost of repairs alone, the interruption in power transfer can result in loss of revenue and can have social implications. The coordination of the strength of the individual components has two main objectives:

- minimising the possibility of cascading failure;

- reducing to a minimum the repair time and cost of a failure.

A proper design of a sequence of failure requires that the component with the lowest reliability level should introduce the least secondary load effects in case of failure. As the failure of the foundation will result in the failure of the entire structure, and will require the most time for repairs, the foundations should be assigned a higher reliability level, as it should be the last component of the structure to fail.

\section{Comparison of the overall factors of safety}

In order to evaluate the influence of partial safety factors proposed in the European standards and used in practice, a simple comparison with evaluation of resulting overall factor of safety (OFS) is presented in Table 1. The use of an analytical model (shear method) was assumed as it involves factors for both, self-weight and additional resistances. Basically, with analytical approach, both standards tackle the verification of uplift ultimate limit strength in similar way, based on the equilibrium model. The main differences are noticeable in the resulting safety level expressed as overall factor of safety.

Both standards, EN 1997-1: 2008 and EN 50431-1: 2012, offer similar levels of reliability. In the case of Eurocode 7 , a significant difference can be noticed between lower and upper bound results; it is an effect of higher partial factor for variable destabilising actions then in EN 50341-1: 2012 and PN-EN 50341-3-22: 2010. Due to the lack of the resistance factor for analytical method presented in Annex M of EN 50341-1: 2012, two values were considered.

Table 1. Comparison of the overall factors of safety (global safety factors) resulting from the use of different approaches in conjunction with analytical methods

\begin{tabular}{|c|c|c|c|c|c|c|}
\hline \multirow[b]{2}{*}{ Standard } & \multirow[b]{2}{*}{ Variant } & \multicolumn{4}{|c|}{ Partial factors of safety } & \multirow{2}{*}{$\begin{array}{l}\text { Overall } \\
\text { Factor of } \\
\text { Safety }^{2}\end{array}$} \\
\hline & & $\begin{array}{l}\text { permanent destabi- } \\
\text { lising action, } \gamma_{G, d s t}\end{array}$ & $\begin{array}{l}\text { variable destabilis- } \\
\text { ing actions, } \gamma_{\mathrm{Q}, \text { dst }}\end{array}$ & $\begin{array}{l}\text { permanent stabi- } \\
\text { lising action, } \gamma_{\mathrm{G}, \mathrm{stb}}\end{array}$ & $\begin{array}{c}\text { resistance, } \\
\gamma_{\mathrm{R}} \text { or } \gamma_{\mathrm{M}}\end{array}$ & \\
\hline \multirow{3}{*}{$\begin{array}{l}\text { EN 1997-1: } \\
2008 \\
\text { - UPL ULS }\end{array}$} & $\begin{array}{c}\text { distinction is made } \\
\text { between } G_{s t b, d} \text { and } \\
R_{d}-\text { drained }\end{array}$ & \multirow{3}{*}{1,00} & \multirow{3}{*}{1,50} & \multirow{3}{*}{0,90} & 1,25 & $1,18-1,77$ \\
\hline & $\begin{array}{l}\text { distinction is made } \\
\text { between } G_{s t b, d} \text { and } \\
R_{d}-\text { undrained }\end{array}$ & & & & 1,40 & $1,26-1,88$ \\
\hline & $R_{d}$ treated as $G_{s t b, d}$ & & & & - & $1,11-1,67$ \\
\hline \multirow{3}{*}{$\begin{array}{l}\text { EN 50341-1: } \\
2012 \\
\text { - GEO ULS }\end{array}$} & $\mathrm{DA} 2^{3)}$ & \multirow{3}{*}{$1,10^{1)}$} & \multirow{3}{*}{$1,30^{1)}$} & - & $\begin{array}{l}1,10 \\
1,40\end{array}$ & $\begin{array}{l}1,21-1,43 \\
1,54-1,82\end{array}$ \\
\hline & DA3 - drained & & & \multirow{2}{*}{$0,90^{1)}$} & 1,25 & $1,30-1,53$ \\
\hline & DA3 - undrained & & & & 1,40 & $1,38-1,63$ \\
\hline
\end{tabular}

1) values introduced by the PN-EN 50341-3-22: 2010 standard, the National Normative Annex to the previous version of the EN 50341-1, the draft for the NNA for the current version is at the consultation stage and the partial factors for actions will be differentiated for three reliability levels.

2) the lower boundary has been calculated for permanent destabilising actions only, while the upper boundary for the variable destabilising actions, the actual overall factor of safety will depend on the permanent/variable ratio; furthermore, the OFS has been calculated under the assumption of equal distribution of the characteristic resistance between the permanent stabilizing actions and additional resistance.

3) The partial safety factor for the resistance is applied to the sum of the permanent stabilising actions and additional resistances; the comparison was made for the range of $1,10-1,40$ as the value for the analytical method is not given in the standard. 
To address the issue of resulting overall factor of safety, as well as to satisfy the conditions of required strength coordination, in practical applications, the partial factors can be further modified by the design specifications provided by the investor or the power line operator. This approach was chosen by the PSE (2014), the largest Polish power lines operator, which published an annex to its specification, requiring the design of the spread foundation loaded in uplift with the resistance factor of 1,40 for design approach DA2* used in Poland (PN-EN 1997-1: 2008/Ap2: 2010). According to the comparison presented in table 1 , this results in overall factor of safety between $1,54-1,82$, based on the ratio of permanent to variable load. Its upper bound gives the reliability level comparable to the one required by the Eurocode 7 in UPL, while the lower bound exceeds that level, indirectly addressing the issue of strength coordination.

Caution is advised in the case of permanent uplift load on a spread foundation. Eurocode 7, as well as EN 50341-1: 2012 standard, offers lower safety margin when permanent load governs the design. However, Pacheco et al. (2008) recommends overall factors of safety of three for permanent, and two for variable load, when uplift resistance of a foundation is considered. Estimated (Table 1) overall factors of safety for variable actions are close to that recommendations. For permanent uplift load the tendency is opposite. Instead of the increase in the factor of safety, both standards offer lower values.

\section{Conclusions and proposal}

The approaches presented by different standards show similarities in the assumptions concerning predicted modes of failures. While basic equilibrium model is considered for verification of uplift resistance, the factors affecting its value are similar regardless of the standard in use. The differences between them result mainly from the value and the application of partial factors, assumed simplifications and disregard for some of the factors that may have significant impact on predicted uplift resistance.

The issues of the reliability and an assumed calculation model should not be considered separately. The former is often guaranteed by the partial safety factors used in the design to take into the account uncertainties that may affect the considered limit state; while the latter should be accompanied by the description of the limitations of the assumed model.

Eurocode 7 offers the most general verification for any type of geotechnical structure subjected to uplift; it considers mainly the possibility of a hydraulic failure, where uplift is caused by a water pressure acting as a permanent destabilising action. On the contrary, the EN 50341-1: 2012 provides more specific guidance; while it might not offer the best available calculation method, it may be the most appropriate with regard to current standard of supervision and execution of construction works. Most spread foundation used for support structures of overhead power lines will fulfil the conditions for shallow foundation model suggested by that stand- ard. However, different models, like those presented in $\mathrm{PN}-80 / \mathrm{B}-03322$, can be used as well if appropriate partial factors are applied.

The analysis presented in the article acts as a preliminary study for future research concerning the subject of the design of spread foundations resisting uplift. Especially, the possibility of calibration of the method used in Poland so far (PN-80/B-03322: 1980) will be taken into consideration as the next step, based on model studies, back-analysis and numerical modelling. Additionally, as the use of numerical methods for uplift resistance calculation is not covered in any of the presented standards, it will also be considered for future research. The finite element method can be used for sensitivity analysis to evaluate the impact of specific factors and uncertainties, as well as to analyse the serviceability limit state in uplift.

\section{References}

EN 1997-1: 2008. Eurocode 7: Geotechnical design-Part 1: General rules.

EN 50341-1: 2012. Overhead electrical lines exceeding $A C$ $1 \mathrm{kV}$ - Part 1: General requirements - Common specifications.

EPRI TR-105000 Project 1493-04 Final Report. July 1995. Reliability-based design of foundations for transmission line structures. New York.

Eskom. 2005. The planning, design \& construction of overhead power lines. Johannesburg: Crown Publications.

IEEE Std 691-2001. IEEE guide for transmission structure foundation design and testing. The Institute of Electrical and Electronics Engineers, Inc. New York, 2001. http://dx.doi.org/10.1109/IEEESTD.2001.93372

Kulhawy, F. H.; Stewart, H. E.; Trautmann, Ch. H. 2003. On the uplift behavior of spread foundations, in Magnan, Droniuc (Eds.). Fondations superficielles. Paris: Presses de l'ENPC/LCPC.

Li, X.; Tian, Y.; Gaudin, Ch.; Cassidy, M. J. 2015. Comparative study of the compression and uplift of shallow foundations, Computers and Geotechnics 69: 38-45. http://dx.doi.org/10.1016/j.compgeo.2015.04.018

Pacheco, M. P.; Danziger, F. A. B.; Pereira Pinto, C. 2008. Design of shallow foundations under tensile loading for transmission line towers: an overview, Engineering Geology 101: 226-235. http://dx.doi.org/10.1016/j.enggeo.2008.06.002

PN-80/B-03322: 1980. Electrical overhead lines. Foundations of structure supports. Static calculations and design.

PN-EN 1997-1: 2008/Ap2: 2010. Eurocode 7: Geotechnical design-Part 1: General rules. National Annex.

PN-EN 50341-3-22: 2010. Overhead electrical lines exceeding AC $45 \mathrm{kV}$ - Part 3: Set of National Normative Aspects.

PSE. 2014. Standard Technical Specification. Overhead Power Line $400 \mathrm{kV}$. Annex 11. Design of the foundations of structure supports for electric overhead lines based on European standards. Konstancin-Jeziorna (in Polish). 